\title{
Effect of spalling thickness on transverse axial bearing capacity of pile foundation under different corrosion depths
}

\author{
Zhongju Feng ${ }^{1}$, Yunhui Guan ${ }^{1}$, Suizhu Guo ${ }^{1}$, Zhouyi Huang ${ }^{2}$, Jingbin $\mathrm{He}^{1}$, Jinhua Chen ${ }^{1}$, Dingran Jiang ${ }^{2}$ \\ ${ }^{1}$ Highway college, Chang'an University, Xi'an, Shaanxi,710064, China. \\ ${ }^{2}$ Guangnan Expressway Investment Construction Development Co. Ltd, 663000, Wenshan, Yunnan, China.
}

\begin{abstract}
The transverse and axial bearing characteristics of bridge pile foundation in salt marsh area are studied by numerical simulation. This paper mainly analyses the change of transverse and axial bearing characteristics of pile foundation caused by the change of spalling thickness of bridge foundation. The results show that the transverse and axial bearing capacity and displacement of pile foundation will be affected by the change of concrete spalling thickness under the condition of pile corrosion. When the peeling thickness is above $9.0 \mathrm{~cm}$, the transverse and axial bearing characteristics of pile foundation are obviously different with the change of corrosion depth of pile body. When the peeling thickness increases and the corrosion depth of the pile body is different, the negative displacement below the zero point of the first displacement of the pile body is continuously reduced, and the displacement curve above the first displacement zero point in the direction of the pile body begins to shift. When the peeling thickness reaches $15.0 \mathrm{~cm}$, the pile top displacement increases to $3.75 \mathrm{~mm}$. The research results are of great significance to the establishment of safety evaluation system of highway bridge pile foundation in alpine salt marsh area, and provide a basis for the structural design of highway bridge pile foundation in alpine salt marsh area.
\end{abstract}

\section{Introduction.}

Bridge pile foundation is the most important bearing structure in the process of bridge use, in addition to being affected by vertical load, it will inevitably be affected by transverse and axial load. Under the influence of various unfavorable conditions, the study of its transverse and axial bearing characteristics is very important ${ }^{[1-5]}$. Zhang Kunyong uses the finite element method to carry out the numerical test on the loading process of the transverse and axial loaded rock-socketed pile, and obtains the load-displacement curve which is consistent with the loading range of the field test, and verifies the rationality of the numerical model ${ }^{[6]}$. Through the analysis of the transverse and axial working performance of the pile foundation of the steep slope bridge in Qinba Mountain area, He Jianjun uses the finite element analysis software to calculate the load transfer mechanism and bearing characteristics of the bridge pile foundation under different slope, pile length and pile diameter in the steep slope section. the variation law of the bearing capacity of the bridge pile foundation and the deformation law of the pile side soil in the steep slope section are obtained ${ }^{[7]}$. Feng Jun made an in-depth study on the transverse and axial bearing characteristics of bridge group pile foundation with high cap in soft soil ${ }^{[8]}$ In recent years, the theoretical research on the transverse and axial bearing characteristics of pile foundation is also in-depth development ${ }^{[9-12]}$. At present, the infrastructure construction of highway transportation in China is developing continuously, and the construction is also widely used in special soil areas. With the progress of the western development strategy, the highway is also constantly advancing to a more complex environment, at the same time, pile foundation as an important part of highway construction, it is necessary to improve the ability of pile foundation to resist complex environment [13-17].

The salt marsh area in northwest China is rich in a variety of corrosive ions. With complex and harsh environmental conditions such as frost heave and carbonization, diseases such as fracture, peeling and peeling appear on the surface of concrete members, resulting in internal loosening of concrete members and reduction of strength, which affects the mechanical properties of concrete materials below the ground of highway bridge pile foundation in varying degrees, affecting the bearing capacity of the bridge. It even makes it impossible to use properly. In saline soil area, under the condition of pile corrosion, under the influence of different thickness of pile concrete spalling, the transverse axial bearing capacity and displacement of pile foundation will also be affected to a certain extent ${ }^{[18-20]}$. 
Therefore, relying on the background of Dexiang Expressway, through numerical simulation, a large number of trial calculations and analysis are carried out on the single pile foundation with different thickness of concrete peeling off under the condition of different depth caused by pile foundation corrosion. The purpose of this paper is to explore the influence of spalling thickness on the transverse and axial bearing characteristics of pile foundation caused by bridge foundation.

\section{Model Establishment and parameter selection.}

\subsection{Geometric model.}

Through the finite element analysis software to establish a finite element model to meet the needs of computing resources, and combined with the bearing characteristics of the pile foundation, after many trial calculations, according to the Saint Venan principle, for the simulation analysis of a single pile, the thickness of the soil at the bottom of the pile is $20 \mathrm{~m}$, and the thickness of the soil on the side of the pile is $8 \mathrm{D}$ ( $\mathrm{D}$ is the diameter of the pile), which can reflect the geometric size and spatial position of the pile and soil, and the spalling thickness of the bridge foundation is selected as $3 \mathrm{~cm}, 6 \mathrm{~cm}, 9 \mathrm{~cm}, 12 \mathrm{~cm}$, $15 \mathrm{~cm}$ and so on.

\subsection{Selection of calculation parameters.}

The difficulty of finite element calculation is to determine the constitutive model which accords with the actual situation and how to select the calculation parameters accurately. After the pile foundation is corroded, the concrete in the pile body will attenuate in quality, and the strength will also decrease accordingly. In the finite element calculation, the attenuation of elastic modulus is used to simulate the actual pile corrosion.

For the characteristic of relative dynamic elastic modulus of concrete, when the finite element parameters are selected, the finite element calculation parameters are selected according to the reduction of relative dynamic elastic modulus determined by indoor corrosion test as the standard. The data of laboratory tests show that when the specimen begins to peel off, the attenuation of its relative dynamic elastic modulus is $80 \% \sim 70 \%$ of that of the beginning. Therefore, in the parameter selection of numerical simulation, the relative elastic modulus of pile foundation is $80 \%, 75 \%, 70 \%$ and $60 \%$ of that at the beginning, respectively, which is used to simulate the corrosion conditions of pile body. Tab. 1 is the parameter selection.

Tab.1 Finite element calculation parameters

\begin{tabular}{|c|c|c|c|c|c|}
\hline Name of material & $\begin{array}{c}\text { Elastic Modulus } \\
\mathrm{E}(\mathrm{MPa})\end{array}$ & $\begin{array}{c}\text { Poisson Ratio } \\
\text { N } \\
\end{array}$ & $\begin{array}{l}\text { Cohesion } \\
\mathrm{c}(\mathrm{kPa})\end{array}$ & $\begin{array}{l}\text { Angle of internal } \\
\text { friction } \\
\varphi\left({ }^{\circ}\right)\end{array}$ & $\begin{array}{l}\text { Bulk density } \\
\gamma\left(\mathrm{kN} / \mathrm{m}^{3}\right)\end{array}$ \\
\hline Pile & $3.0 \times 10^{4}$ & 0.20 & - & - & 25.0 \\
\hline Fine sand & 12.5 & 0.33 & 10.8 & 30 & 18.4 \\
\hline Silty clay & 5.6 & 0.30 & 20 & 20 & 18.3 \\
\hline Spalling concrete & $2.4 \times 10^{4}$ & 0.20 & - & - & 25.0 \\
\hline Exfoliation $9.0 \mathrm{~cm}$ & $2.3 \times 10^{4}$ & 0.20 & - & - & 25.0 \\
\hline Exfoliation $12 \mathrm{~cm}$ & $2.1 \times 10^{4}$ & 0.20 & - & - & 25.0 \\
\hline Exfoliation $15 \mathrm{~cm}$ & $1.8 \times 10^{4}$ & 0.20 & - & - & 25.0 \\
\hline
\end{tabular}

\section{Calculated working condition.}

The environment in the alpine saline soil area is bad, under the condition of dry-wet cycle and salt corrosion, the concrete members of the underground pile will fall off seriously, and even the reinforcement will be exposed. In order to further study the transverse and axial bearing characteristics of bridge pile foundation in saline soil area, relying on the Qinghai Dexiang highway project, and analyzing the research on the lower corrosion structure of bridges and culverts in Qinghai at the same time, it is found that the corrosion phenomenon mainly occurs between $1.0 \mathrm{~m}$ above the ground and the groundwater level. The muddy silt and saturated fine sand in the road area where Dexiang Expressway is located are mainly concentrated in $8.0 \mathrm{~m}$ below the surface, so the corrosion depth (defined as the corrosion zone height of pile foundation below ground, represented by symbol $\mathrm{H}$ ) can be considered in the design of working conditions. the corrosion depth can be $0.0 \mathrm{~m}, 1.5 \mathrm{~m}, 3.5 \mathrm{~m}$, $5.0 \mathrm{~m}$ and $8.0 \mathrm{~m}$, respectively. Meanwhile, spalling thickness (decrease of force section of pile body, radius decrease with symbol $\delta$ ) increases with corrosion period, concrete spalling thickness is $0.0 \mathrm{~cm}, 3.0 \mathrm{~cm}, 6.0 \mathrm{~cm}$, $9.0 \mathrm{~cm}, 12 \mathrm{~cm}, 15 \mathrm{~cm}$. Specific calculation conditions are shown in Tab.2.

Tab.2 Calculation conditions of spalling thickness change
Spalling thickness
Pile diameter
Pile length
Depth of decay
$\delta(\mathrm{cm})$
$\mathrm{D}(\mathrm{m})$
L (m)
$\mathrm{H}$ (m) 


$$
\text { 0、3、6、9、12、15 } 1.8 \quad 40 \quad 1.5,3.5 、 5.0 、 8.0
$$

\section{8}

When pile length is $40 \mathrm{~m}$ diameter of $1.8 \mathrm{~m}$ pile diameter is invariable, the thickness change of pile foundation is changed. Using transverse and axial loading method, the influence of thickness variation of pile foundation on bearing characteristics of pile foundation is studied. The variation rule of pile foundation bearing capacity $\mathrm{H}-\mathrm{y}$ curve is shown in Fig.1.

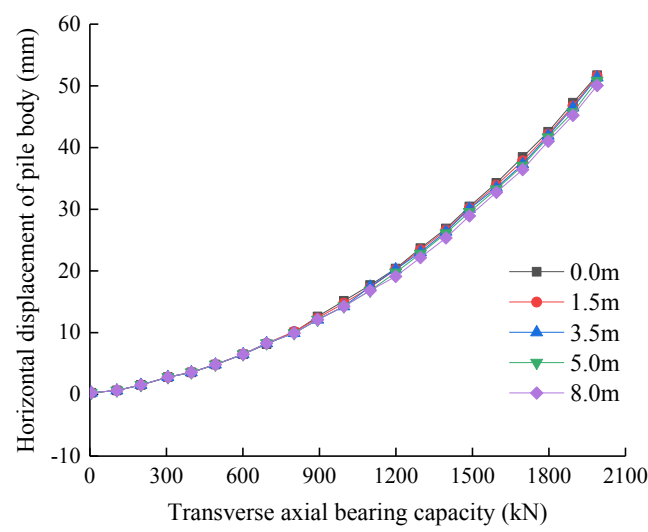

(b) $86.0 \mathrm{~cm}-\mathrm{D} 1.8-\mathrm{L} 40$

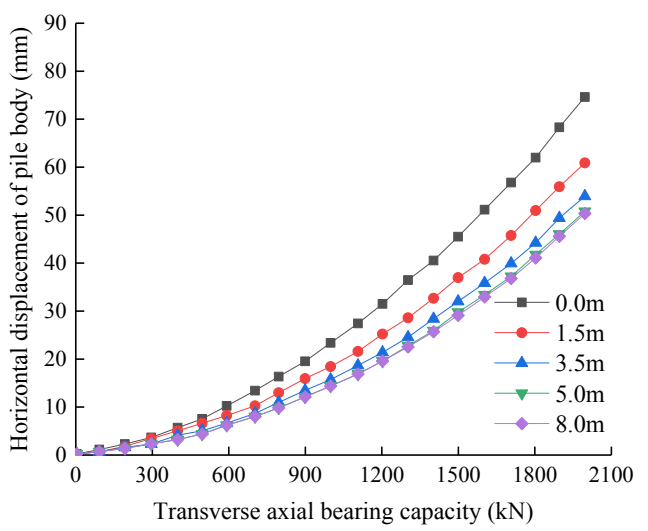

(d) $812.0 \mathrm{~cm}-\mathrm{D} 1.8-\mathrm{L} 40$

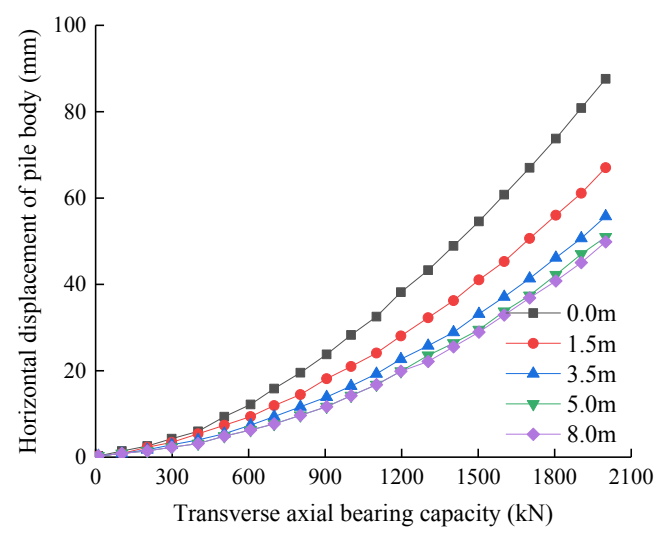

(d) $815.0 \mathrm{~cm}-\mathrm{D} 1.8-\mathrm{L} 40$

Fig.1 Effect of peeling thickness variation under different pile diameters on transverse and axial bearing capacity of pile foundation 
$3.0 \mathrm{~cm}$ and $6.0 \mathrm{~cm}$, transverse and axial bearing capacity of pile body does not change obviously due to the change of depth of pile body corrosion. This is because when spalling thickness is relatively small concrete protective layer has not completely shed therefore pile body structure is relatively complete use safety. Comparing graphs c, figure $\mathrm{d}$ and figure e shows that when spalling thickness reaches more than $9.0 \mathrm{~cm}$ transverse and axial bearing capacity of pile body increases obviously with variation of corrosion depth of pile body. Taking spalling thickness of $9.0 \mathrm{~cm}$ as an example, it can be found that transverse and axial displacement of pile foundation decreases with increasing corrosion depth when transverse and axial displacement of pile top is $60 \mathrm{~mm}$. When corrosion depth is $8.0 \mathrm{~m}$ pile body, the lowest transverse and axial bearing capacity is only $1700 \mathrm{kN}$.

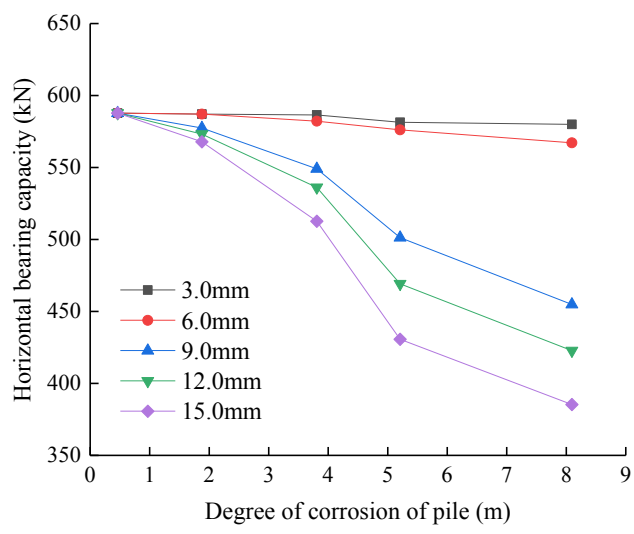

Fig.2 Variation of transverse and axial bearing capacity with different peeling thickness

From Fig.2, it can be concluded that the change of spalling thickness affects transverse and axial bearing capacity under different corrosion depth, and there is obvious difference between transverse and axial bearing capacity of $9.0 \mathrm{~cm}, 12.0 \mathrm{~cm}$ and $15.0 \mathrm{~cm}$. When thickness of spalling thickness is $9.0 \mathrm{~cm}$ and corrosion depth is $1.5 \mathrm{~m}$, transverse and axial bearing capacity decreased from $587.04 \mathrm{kN}$ to $586.06 \mathrm{kN}$, decrease of $0.2 \%$; When corrosion depth is $3.5 \mathrm{~m}$, transverse and axial bearing capacity decreased from $587.04 \mathrm{kN}$ to $548.95 \mathrm{kN}$, decrease of $6.5 \%$; When corrosion depth is $5.0 \mathrm{~m}$, transverse and axial bearing capacity decreased from $587.04 \mathrm{kN}$ to $500.44 \mathrm{kN}$, decrease of $14.8 \%$; When corrosion depth is $8.0 \mathrm{~m}$, transverse and axial bearing capacity decreased from $587.04 \mathrm{kN}$ to $453.37 \mathrm{kN}$, decrease of $22.8 \%$. When thickness of spalling thickness is $12 \mathrm{~m}$ and corrosion depth is $1.5 \mathrm{~m}$, transverse and axial bearing capacity decreased from $587.04 \mathrm{kN}$ to $575.23 \mathrm{kN}$, decrease of $2 \%$;
When corrosion depth is $3.5 \mathrm{~m}$, transverse and axial bearing capacity decreased from $587.04 \mathrm{kN}$ to $534.92 \mathrm{kN}$, decrease of $8.9 \%$; When corrosion depth is $5 \mathrm{~m}$, transverse and axial bearing capacity decreased from $587.04 \mathrm{kN}$ to $471.53 \mathrm{kN}$, decrease of $19.7 \%$; When corrosion depth is $8 \mathrm{~m}$, transverse and axial bearing capacity decreased from $587.04 \mathrm{kN}$ to $422.72 \mathrm{kN}$, decrease of $28.0 \%$. When thickness of spalling thickness is $15 \mathrm{~m}$ and corrosion depth is $1.5 \mathrm{~m}$, transverse and axial bearing capacity decreased from $587.04 \mathrm{kN}$ to $569.01 \mathrm{kN}$, decrease of $3.1 \%$; When corrosion depth is $3.5 \mathrm{~m}$, transverse and axial bearing capacity decreased from $587.04 \mathrm{kN}$ to $511.20 \mathrm{kN}$, decrease of $12.9 \%$; When corrosion depth is $5.0 \mathrm{~m}$, transverse and axial bearing capacity decreased from $587.04 \mathrm{kN}$ to $430.86 \mathrm{kN}$, decrease of $26.6 \%$; When corrosion depth is $8 \mathrm{~m}$, transverse and axial bearing capacity decreased from $587.04 \mathrm{kN}$ to $385.12 \mathrm{kN}$, decrease of $34.4 \%$.

Tab 3. Allowable bearing capacity and reduction range

\begin{tabular}{|c|c|c|c|c|c|c|c|}
\hline \multicolumn{3}{|c|}{$\begin{array}{l}\text { Depth of decay } \\
\text { Allowable } \\
\text { bearing capacity } \\
\text { Reduction amplitude }\end{array}$} & \multirow[t]{2}{*}{$0.0 \mathrm{~m}$} & \multirow[t]{2}{*}{$1.5 \mathrm{~m}$} & \multirow[t]{2}{*}{$3.5 \mathrm{~m}$} & \multirow[t]{2}{*}{$5.0 \mathrm{~m}$} & \multirow[t]{2}{*}{$8.0 \mathrm{~m}$} \\
\hline $\begin{array}{l}\text { Pile } \\
\text { length } \\
\text { (m) }\end{array}$ & $\begin{array}{c}\text { Pile } \\
\text { diameter } \\
(\mathrm{m})\end{array}$ & $\begin{array}{c}\text { Spalling } \\
\text { thickness } \\
(\mathrm{cm})\end{array}$ & & & & & \\
\hline \multirow{5}{*}{40} & \multirow{5}{*}{1.8} & 3.0 & $587.04 / 0.0$ & $586.57 / 0.1$ & $584.85 / 0.4$ & $581.28 / 1.0$ & $577.45 / 1.6$ \\
\hline & & 6.0 & $587.04 / 0.0$ & $586.06 / 0.2$ & $582.36 / 0.8$ & $575.5 / 2.0$ & $567.5 / 3.3$ \\
\hline & & 9.0 & $587.04 / 0.0$ & $578.67 / 1.4$ & $548.95 / 6.5$ & $500.44 / 14.8$ & $453.37 / 22.8$ \\
\hline & & 12 & $587.04 / 0.0$ & $575.23 / 2.0$ & $534.92 / 8.9$ & $471.53 / 19.7$ & $422.72 / 28.0$ \\
\hline & & 15 & $587.04 / 0.0$ & $569.01 / 3.1$ & $511.2 / 12.9$ & $430.86 / 26.6$ & $385.12 / 34.4$ \\
\hline
\end{tabular}




\subsection{Effect of thickness variation on transverse and axial displacement of pile foundation under different corrosion depth.}

Under the condition that the pile length is $40 \mathrm{~m}$ and the diameter is $1.8 \mathrm{~m}$, the spalling thickness of the bridge foundation changes. The influence of the spalling

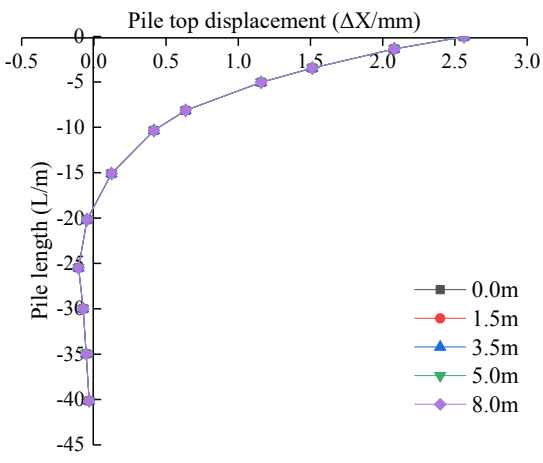

(a) $83.0 \mathrm{~cm}-\mathrm{D} 1.8-\mathrm{L} 40$

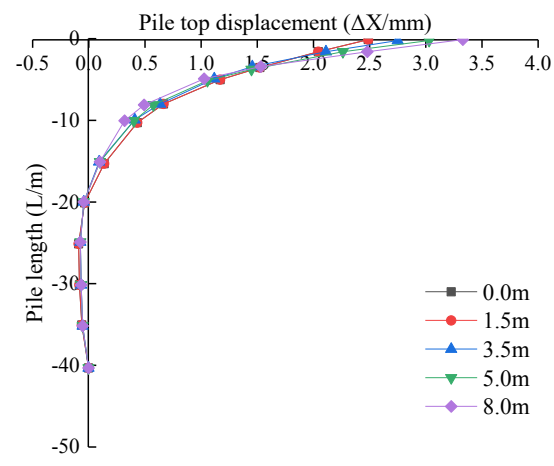

(c) $89.0 \mathrm{~cm}-\mathrm{D} 1.8-\mathrm{L} 40$ thickness of the pile foundation on the bearing characteristics of the pile foundation is studied by using the method of transverse axial graded loading. Under the condition that the corrosion depth of the pile body changes, the transverse axial displacement curve of the pile foundation along the pile direction is shown in Fig 3 .

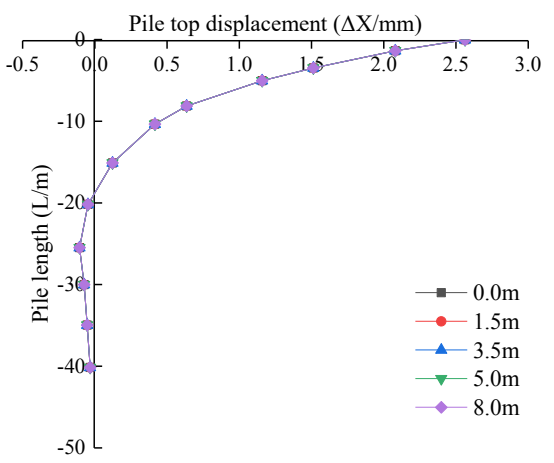

(b) $86.0 \mathrm{~cm}-\mathrm{D} 1.8-\mathrm{L} 40$

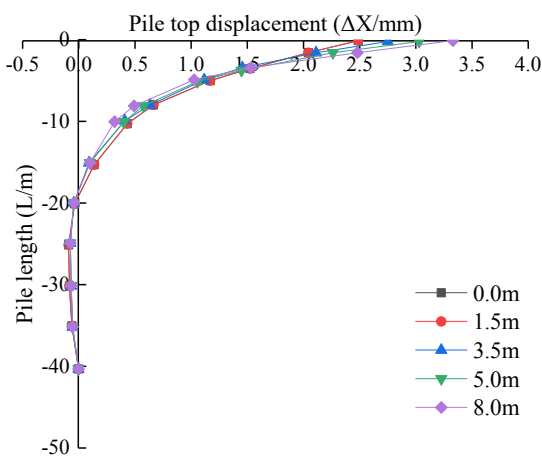

(d) $\delta 12 \mathrm{~cm}-\mathrm{D} 1.8-\mathrm{L} 40$

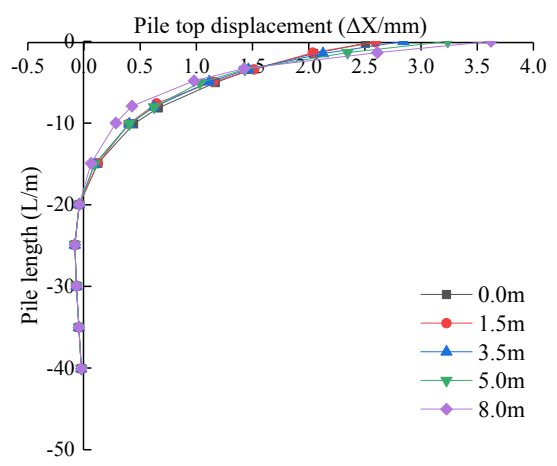

(e) $\delta 15 \mathrm{~cm}-\mathrm{D} 1.8$-L40

Fig 3. Transverse and axial displacement curve of pile body direction with variation of corrosion depth under different peeling thickness conditions

According to curve analysis of graph $\mathrm{f}$ and graph $\mathrm{g}$, there is no obvious change in transverse and axial displacement of pile body when thickness of pile body changes when thickness of flake is $3.0 \mathrm{~cm}$ and $6.0 \mathrm{~cm}$ respectively. Because the thickness of spalling is not large enough, the protective layer of concrete is not completely exfoliated and reinforcement parts are not obvious, thus showing that when thickness of flake is 
$3.0 \mathrm{~cm}$ and $6.0 \mathrm{~cm}$, it shows that the protective layer is not obvious. The depth of pile body corrosion has little influence on transverse and axial displacement and safety of pile foundation structure is relatively small.

The comparison shows that the negative displacement below the zero point of the first displacement of the pile decreases with the increase of the spalling thickness. Comparing graphs $\mathrm{c}$ diagram $\mathrm{d}$ and $\mathrm{e}$, we can see clearly that when the thickness of spalling becomes larger the displacement curve of the first displacement of pile direction is shifted above zero point at different depth of pile body corrosion depth when spalling thickness becomes larger. Even when the thickness of spalling reaches $15 \mathrm{~cm}$, the pile top displacement reaches $4.2 \mathrm{~mm}$. This indicates that with increasing spalling thickness transverse and axial displacement of pile body will change with depth of pile body after exposed. Pile foundation stability has been greatly influenced.

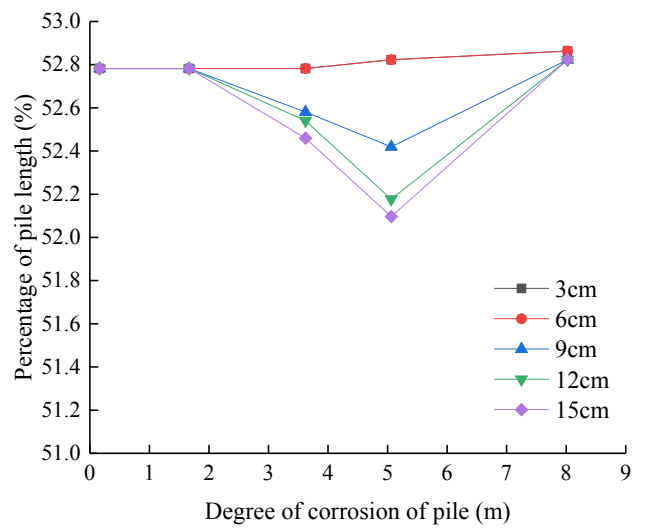

Fig 4. Percentage of pile length from zero point of transverse and axial displacement to pile bottom under different peeling thickness

Meanwhile, at the same time, it is of great significance to study the relative position change of the first displacement zero in the pile body. As can be seen from figure 4: taking the spalling thickness of $15 \mathrm{~cm}$ as an example, when the corrosion depth of the pile is $0.0 \mathrm{~m}$, the position of the zero point of the first horizontal displacement is $18.888 \mathrm{~m}$ from the top of the pile, accounting for $47.2 \%$ of the length of the pile; When the corrosion depth of the pile is $1.5 \mathrm{~m}$, the position of the first horizontal zero is $18.900 \mathrm{~m}$ from the top of the pile, accounting for $47.2 \%$ of the length of the pile; When the corrosion depth of the pile is $3.5 \mathrm{~m}$, the position of the first horizontal zero is $19.001 \mathrm{~m}$ from the top of the pile, accounting for $47.5 \%$ of the length of the pile; When the corrosion depth of the pile body is $5.0 \mathrm{~m}$, the position of the first horizontal zero is $19.167 \mathrm{~m}$ from the top of the pile, accounting for $47.9 \%$ of the pile length; when the corrosion depth of the pile body is $8.0 \mathrm{~m}$, the position of the first horizontal zero is $18.839 \mathrm{~m}$ from the top of the pile, accounting for $47.1 \%$ of the pile length.

\section{Conclusion.}

(1) The thickness of spalling affects transverse and axial load characteristics under different depth under different depth of decay. When the thickness of pile body spalling is relatively small, transverse and axial load bearing characteristics of pile foundation does not change obviously because of corrosion depth of pile foundation; When spalling thickness reaches more than $9.0 \mathrm{~cm}$, transverse and axial load characteristics of pile foundation occur obviously with variation of corrosion depth of pile body.
(2) When the transverse and axial bearing capacity of pile foundation is at the same depth of decay, the decrease amplitude increases with increasing thickness of pile body spalling. When the thickness of spalling is above $9.0 \mathrm{~cm}$, its decrease amplitude increases obviously.

(3) With the increase of the spalling thickness, the negative displacement below the zero point of the first displacement of the pile body is decreasing, and the displacement of the pile top is increasing; under the same corrosion depth, different spalling thickness will also affect the position of the zero point of the first displacement, that is, the greater the spalling thickness, the farther the position of the first displacement zero from the top of the pile, especially when the corrosion depth is $5 \mathrm{~m}$.

\section{References:}

[1] Li Li-yun,Li, Jin-long. Ultimate Bearing Capacity of Soil in Transverse and Axial Pipe-Sand Interaction $[\mathrm{J}]$. Journal of Beijing University of Technology, 2016, 42 (06): 933-938.

[2] Zhao Ming-hua, Huang Li-xiong, Liu Si-si. Analysis of the influence of transverse and axial loads on the vertical bearing capacity of foundation piles[J].Highway Transportation Science and Technology, 2009,26(07): 44-48.

[3] Jin Qing, Cui Xin-zhuang, Liu Zheng-gen. Numerical Analysis of Transverse and Axial Bearing Capacity of Rigid Piles [J]. Geotechnical Mechanics, 2006,27(S2):814-817.

[4] Cui Xin-zhuang, Ding Ye, Jin Qin. Three-dimensional limit analysis of transverse and axial bearing capacity of rigid piles [J].Journal of Rock Mechanics and Engineering, 2006 (03): 
641-646.

[5] $\mathrm{Xu} \mathrm{He}, \mathrm{Xu}$ Min-ruo, Zheng Chun-sheng. Experimental study on transverse and axial bearing capacity of single pile[J].Journal of Geotechnical Engineering, 1982(03): 27-42.

[6] Zhang Kun-yong, Li Guang-shan, Du Wei. Study on the transverse and axial bearing capacity of rock-socketed piles based on numerical tests[J].Journal of Sichuan University (Engineering Science Edition), 2016,48(06): 58-67.

[7] He Jian-jun. Performance Analysis of Bridge Pile Foundation under Transverse and Axial Loading in Steep Slope Section of Qinba Mountains [D]. Chang'an University, 2010.

[8] Feng Jun, Zhang Jun-yun, Zhu ming, Jiang Nan. Study on Transverse and Axial Bearing Behavior of Pile Group Foundation of High Cap Bridge in Soft Soil Stratum[J].Geotechnical Mechanics, 2016,37(S2): 94-104.

[9] Deng Tao, Lin Cong-yu, Liu Zhi-peng etc. A Simple Elastoplastic Method for Calculating Horizontal Loaded Single Pile under Large Displacement [J/OL]. Geotechnical Mechanics, 2020 (01): 1-8

[10] Xiong Hui, Yang Feng. Horizontal Vibration Response Analysis of Liquefied Soil Pile Foundation under Winkler Foundation Model [J/OL]. Geotechnical Mechanics, 2020 (01): 1-9

[11] Qin Wu, Zhou Xiao-chun, Yu Chang-zhu etc. Design and Construction of Rock-socketed Cast-in-place Pile Foundation under Thick and Strong Weathering Geological Conditions [J/OL]. Waterway Engineering: 1-6

[12] Wang Shu, Duan Wei-hong, Ma Chong etc. Horizontal Bearing Capacity Analysis of Pile Foundation Based on In-situ Testing Technology of Geotechnical Engineering[J].Safety and Environmental Engineering, 2018,25(06): 183-190.

[13] Yibo Wang,Xiong Xia,Yan Wu. Model Experimental Study on Support Structure of Double-row Piles in Deep Foundation Pit[J]. IOP Conference Series: Earth and Environmental Science,2019,267(3).

[14] Zheng Li, Ding Bai-wei, Liu Bo-quan etc. Application of post-grouting technology of pile foundation in karst area of high-speed railway[J].Subgrade Engineering, 2018(02): 155-159+169.

[15] Zhu Guo-Xiang, Feng De-fei. Optimum Design of Long Pile Number of Diameter Pile in Pile Foundation of Highway Bridge[J].Highway Transportation Science and Technology (Applied Technology Edition), 2018,14(07): 191-193.

[16] Jiale Li,Xuefei Wang,Yuan Guo,Xiong (Bill) Yu. Vertical bearing capacity of the pile foundation with restriction plate via centrifuge modelling[J]. Ocean Engineering,2019,181.

[17] A A Kovalevsky,I A Skurtol. The Factor of "Synergy" in the Design and Construction of Foundations of Driven Piles[J]. IOP Conference Series: $\quad$ Earth and Environmental
Science,2019,272(3).

[18] Feng Zhong-ju, Wang Fu-chun, Zhang Qi-lang etc. Centrifugal Model Test on Transverse and Axial Bearing Behavior of Concrete Filled Steel Tubular Composite Piles[J].Journal of Civil Engineering, 2018,51(01): 114-123+128.

[19] Yao Xian-hua, Feng Zhong-ju, Wang Fu-chun etc. Corrosion Resistance Test of Pile Foundation Materials for Highway Bridges in Salt Marsh Environment[J].Journal of Chang'an University (Natural Science Edition), 2018,38(01): 49-58.

[20] Feng Zhong-ju, Chen Si-xiao, Xu Hao etc. Durability evaluation of concrete in Alpine salt marsh area based on grey system theory[J].Journal of Transportation Engineering, 2018,18(06): 18-26. 